\title{
Community Co-design of a Geospatial Linked Open Data Platform for Environmental Management
}

\author{
J. O'Flaherty
}

The National Microelectronics Applications Centre Ltd, Limerick, Ireland

\begin{abstract}
SDI4Apps is an EU project that is building a cloud-based Geospatial Linked Open Data platform for data integration, to bridge from the top-down managed world of Geospatial Information to the bottom-up user-driven mobile world of Linked Open Data voluntary initiatives and micro SMEs developing applications using the information. To ensure its success, SDI4Apps has ensured the active participation of user communities in its co-design and validation through the implementation of 6 varied pilots involved in environmental management across Europe. Successful implementation of the SDI4Apps user communities' participation and their social validation is described in this paper. The social validation methodology has included development of specific criteria for measuring the platform's success, methods for multi-stakeholder social participation, analysis for internal and external communities and a clear set of indicators, which are now being measured during the validation process based on structured pilot scenarios. This robust stakeholders' involvement methodology, which is central to SDI4Apps, is not only generating sustainable economic returns through the interface between the users, SMEs, policy makers and scientific communities, but guarantees a solid contribution to the knowledge-driven economy and environmental management across Europe.
\end{abstract}

\section{Key words}

Geospatial Information, Linked Open Data, Environmental Management, SDI4Apps, Social Validation, Community Co-design, European Project.

\section{Introduction}

The potential of Geographic Information (GI) collected by various actors ranging from public administration to voluntary initiatives of citizens is not fully exploited. The advancements of Information and Communications Technologies (ICT) and the shift towards Linked Open Data (LOD) gives an excellent foundation for innovation based on the reuse of GI (Abbas and Ojo, 2013). The establishment of Spatial Data Infrastructures (SDI) has largely been driven by the "traditional" GI community and the national and European policies governing this sector. However now GI is no longer a separate information space but finds itself part of a larger European information space where the ultimate objective is the creation of value-added services based on use and reuse of public sector information as defined by the Public Sector Information (PSI) and Infrastructure for Spatial Information in the European Community (INSPIRE) Directives rather than exchange of "layers" between different GI software (Vilches-Blázquez, Saquicela and Corcho, 2012).

\section{Material and methods}

SDI4Apps (Uptake of open geographic information through innovative services based on linked data) is an EU Competitiveness and Innovation Programme (CIP) pilot action project that aims to bridge from the top-down managed world of INSPIRE, Copernicus and Global Earth Observation System of Systems (GEOSS) Geospatial Information (GI) to the bottom-up mobile world of LOD voluntary initiatives and micro SMEs developing applications based on GI and LOD. SDI4Apps is adapting and integrating experience from previous projects and initiatives to build a cloud based LOD framework with an open Applications Programme Interface (API) for data integration, easy access and provision for further reuse (Figure 1: Charvat, Mildorf, Tuchyna, Vohnout and Krivanek, 2014).

The SDI4Apps project is integrating a cloud-based platform for data reuse. On that platform, several user-driven applications (pilot apps) are being designed and implemented (Figure 2).

To ensure its success, SDI4Apps requires 


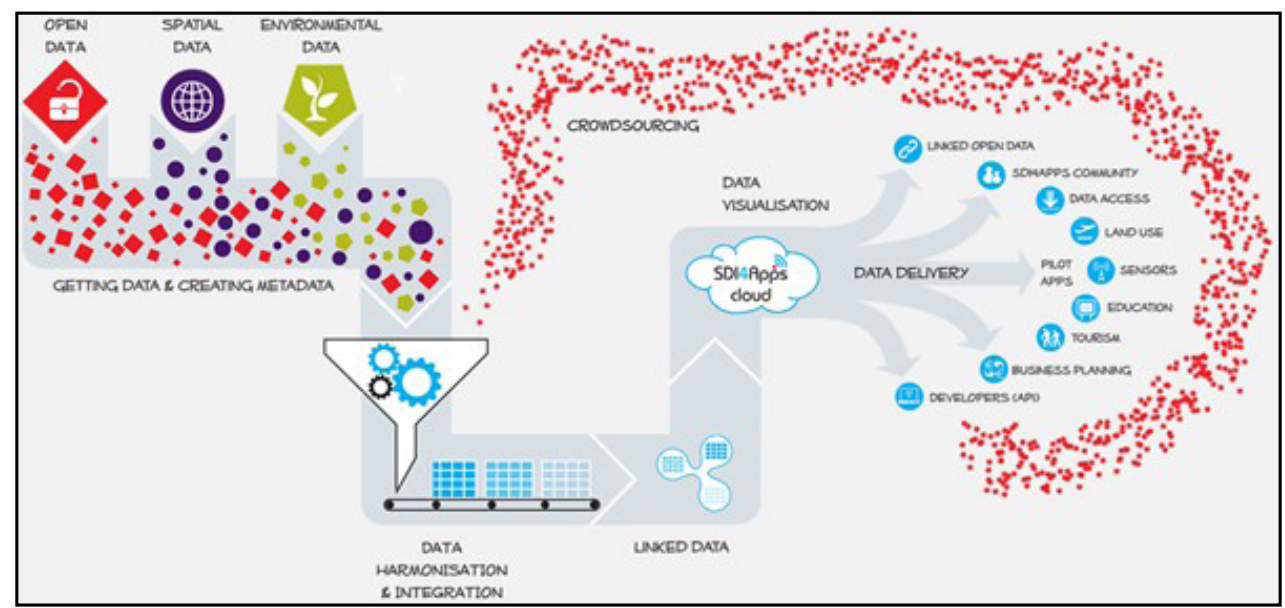

Source: Charvat, Mildorf, Tuchyna, Vohnout and Krivanek, 2014

Figure 1: SDI4Apps Platform.

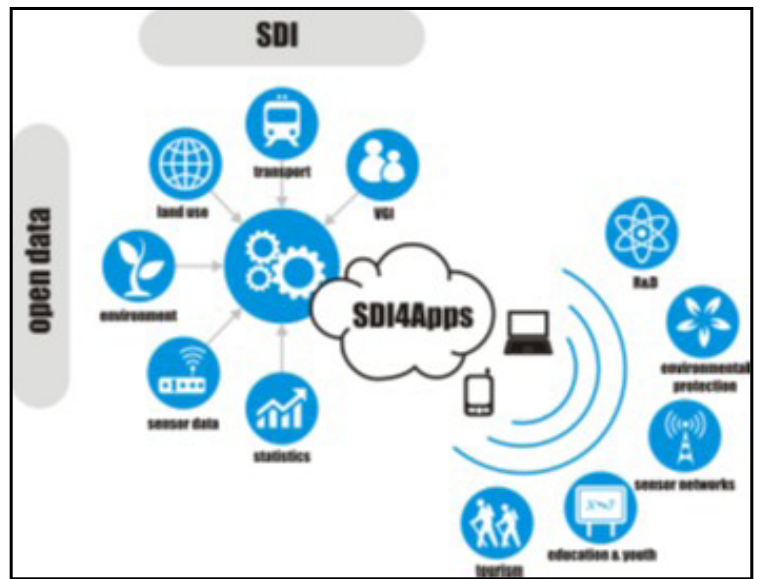

Source: Charvat, Mildorf, Tuchyna, Vohnout and Krivanek, 2014

Figure 2: SDI4Apps Pilot Applications.

the active participation of user communities in its co-design and validation through the implementation of 6 varied pilots involved in environmental management across Europe. These pilots include:

1. Easy Data Access - supporting easy access to existing services and integrate an API solution, to facilitate easy collection of information using smart phones and integrate this information into current SDIs.

2. Open Smart Tourist Data - supporting related business issues such as easy integration of the SDI4Apps system into proprietary solutions (thanks to the implementation of standards), reusing and sharing existing information resources, channels and tools. Open Smart Tourist Data is integrating users' data, free and open global data, SDI4Apps Team's data, crowd-sourced data and social media.(Vohnout, Cerba, Kafka,
Fryml, Krivanek and Holy, 2014; Karam and Melchiori, 2013)

3. Open Sensors Network - to create an environment where different groups of volunteers (for example farmers) are able to integrate low cost sensors (meteorological, quality of air, etc.) into local and regional web sensor networks.

4. Open Land Use Map Through VGI - an initiative for voluntary Open Land Use Mapping.

5. Open INSPIRE4Youth - to generate local educational multilingual environmental and cultural heritage applications for students and youth.

6. Ecosystem Services Evaluation - focused on the sustainable support of tourism.

The SDI4Apps platform and tools are being community co-designed and socially validated 
through these 6 deployed community pilot demonstrators that will be technically evaluated for:

1. the effectiveness of the approach for the Cloud, LOD and semantic services (Kritikos, Rousakis, and Kotzinos, 2013);

2. how well the proposed architecture can be adapted to different scenarios (Metzger, Flanagin and Medders, 2010)

3. the limitations and benefits of the approach compared to existing technologies.

Community-based businesses foster trust, commitment, high-quality of products and services, accountability, social-environmental responsibility, business ethics, and "contagious commitment". Thus in each of the 6 SDI4Apps pilots, the project nurtures the Service Provider and User concept and makes them both integral to the community co-design and social validation participatory process so that it becomes accepted as a necessary interchange and form part of an emerging business environment. The robust stakeholder involvement central to SDI4Apps is not only generating sustainable economic returns through the interface between the business and the scientific community, but guarantees a solid contribution to a knowledgedriven economy and environmental management in Europe. The long-term sustainable implementation of the SDi4Apps platform depends on three main pillars:

1. A large user community with strong commitment (based on involvement, trust and the benefits they receive from using the services).

2. A reliable supply of global SDI data content, guaranteed large scale of services.

3. A thriving private sector of small enterprises (individuals, SMEs and NGOs) that provide value-added services of mutual benefit to all involved.

\section{Stakeholders and user groups}

SDI4Apps is building user communities that actively participate in the processes of design, integration, validation and uptake of the proposed SDI4Apps cloud platform. The specific operational objectives include (Elwood, Goodchild and Sui, 2012):

- community building and management with a focus on pilot regions and potential external users and developers:

- launch and maintain the SDI4Apps platform for the consolidation of its user communities and their structured participation in key project activities;

- engage stakeholders involved in SDI4Apps pilot services on the one hand, and participants in the extensive thematic, global and trans-European networks represented by project partners on the other hand, for active participation in the SDI4Apps communities (Norton and Krummenacher, 2010);

- working with the SDI4Apps communities to develop user scenarios exploiting the availability of harmonised and interoperable data sets and services to access INSPIRE-related data by a large and extended community;

- define a validation methodology for internal and external validation of the platform

- on the basis of the project results and especially the outcomes of the validation pilot services, assess the potential impact of scaled-up adoption of SDI4Apps metadata profiles, data models and SDI services on environment-related activities that they carry out in their daily work;

- support the social validation of the system by internal user groups and external communities, and provide feedback for the technical teams.

This building of a community around the SDI4Apps Cloud, is based on a core community represented by the project partners. This community is being extended by other related communities and through organising sprint code workshops and developers' contests, as follows (Figure 3):

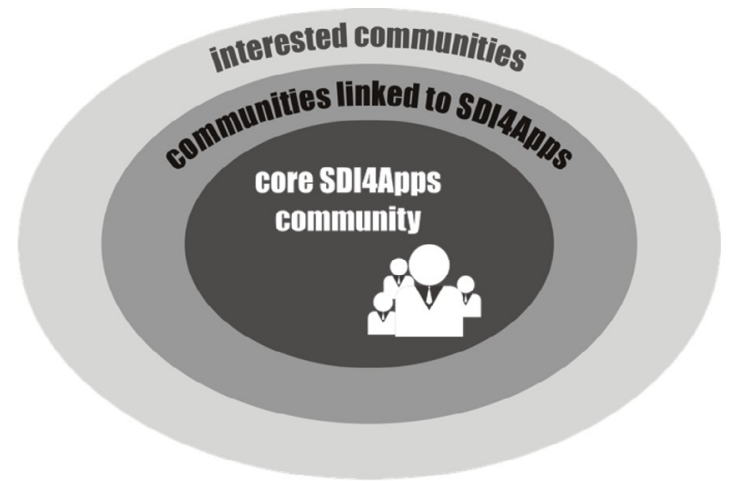

Source: Charvat, Mildorf, Tuchyna, Vohnout and Krivanek, 2014 Figure 3: Learning Community Space. 
While the stakeholder mapping emphasizes the institutional/market relationships between the stakeholders driving their transactions, it is also necessary to model the technical level at which the pilot is operating and the different layers of services involved.

The stakeholder and layered service models adopted in SDI4Apps have been developed from the ICTENSURE project (ICT-ENSURE), which explored the broad dynamics of the contribution of ICT towards environmental sustainability, considering GI and LOD as important components Figure 4).

The SDI4Apps stakeholder mapping, based on ICT-ENSURE's analysis of the environmental management problem space, is based on institutional, operational, and economic standpoints related to the environment, and the key roles were identified as follows:

- Governments and policy-makers: mainly as funders of environmental research, the initiators of top-down actions such as SISE and SEIS, and generally institutionally mandated for the implementation of INSPIRE and open data standards. In SDI4Apps, different levels of government are represented in all of the pilot communities.

- - Environmental experts: experts in the field of the environment (generally universities or government bodies) applying GI and LOD to improve their capacity to monitor and predict; these actors generally assume an observational stance with respect to the environment, and are also present in several but not all of the SDI4Apps pilots
- ICT and sector industries: this includes in the broadest sense industrial activities with an effect on the environment, i.e. tourist organisations, agro-food multinationals, the construction industry, etc.; these stakeholders are present in several but not all of the SDI4Apps pilots. This category also includes the ICT industry and its potential interest in adopting and building its services on top of the SDI4Apps platform. Many SDI4Apps partners therefore fall into this category.

- Multi-disciplinary research: this groups socio-economic and ICT researchers into a multi-disciplinary perspective on the SDI4Apps problem space as a question of sustainable development including both the environment and human communities within it; this group drives some of the SDI4Apps pilots, particularly those with a stronger Living Lab approach.

- Stakeholder communities: these are the associations, local NGOs, etc. who represent those directly affected by environmental change; they are involved primarily in information management, dissemination and awareness activities; these actors can be said to be "inside" the environment rather than observing it and are often the "champions" within SDI4Apps pilot communities.

While the following figure illustrates the layered mapping of stakeholders for ICT services such as those that are enabled by the SDI4apps Platform (Figure 5).

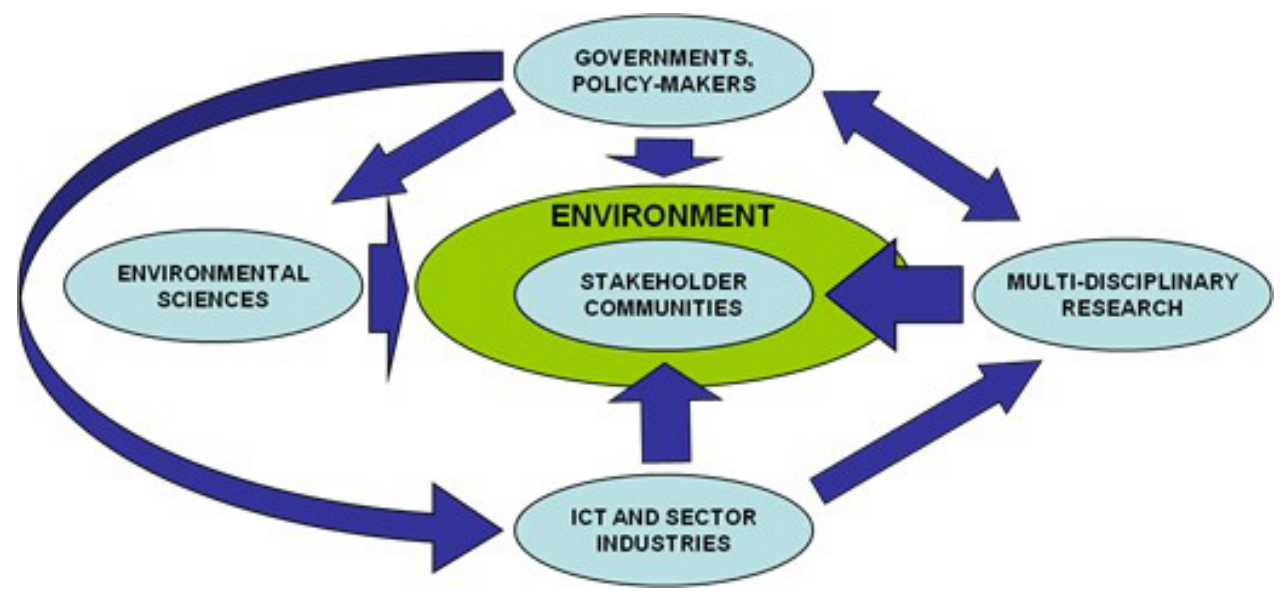

Source: Charvat, Mildorf, Tuchyna, Vohnout and Krivanek, 2014

Figure 4: SDI4Apps stakeholder mapping. 


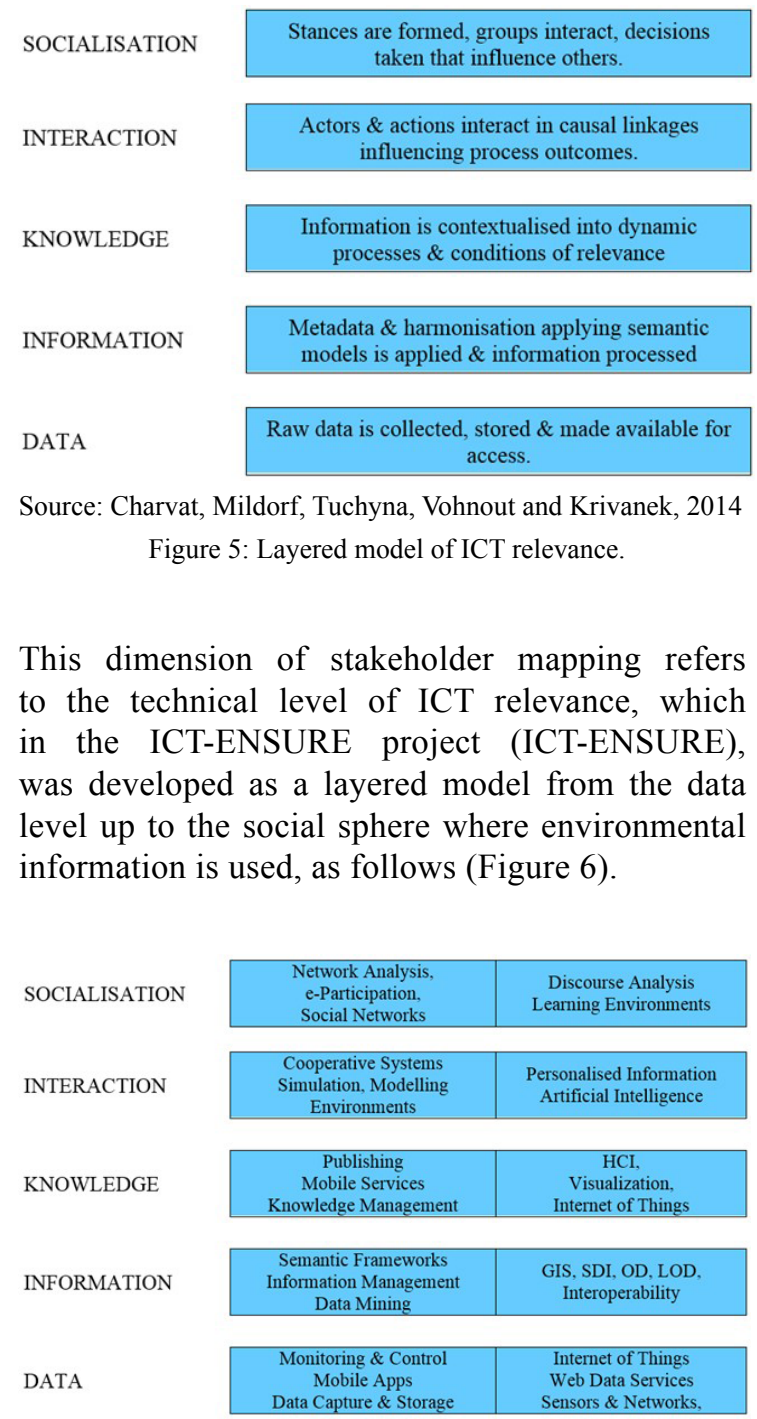

Source: Charvat, Mildorf, Tuchyna, Vohnout and Krivanek, 2014 Figure 6: Layered ICT infrastructures and services.

This model can be directly related to the different levels of social validation with respect to data modelling at one extreme and end-user services at the other. It is useful to see how each layer associates with the relevant ICT infrastructures, services, and research fields that can make a contribution to environmental management. Many of the technologies listed here have in fact been adopted and/or explored by SDI4Apps pilots.

With specific relevance to the SDI4Apps project, the same layers can finally be developed as supporting different levels of the SDI4Apps platform-based community co-designed services, from the data access level to community and social networking services (Fig. 7).

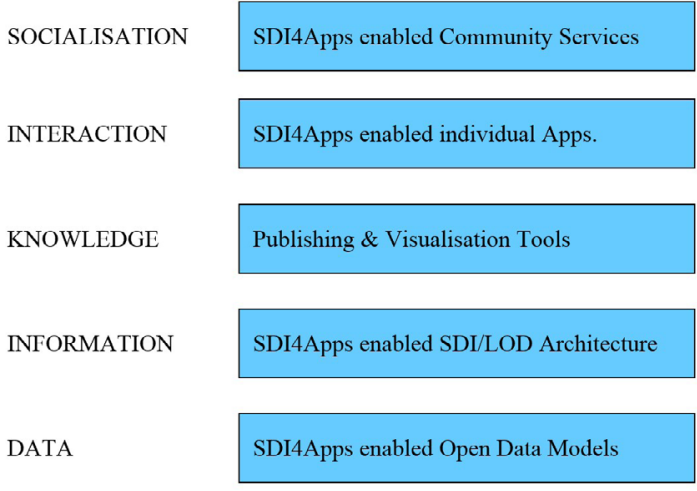

Source: SDI4Apps Social Validation Methodology

Figure 7: SDI4Apps-based infrastructure and service layers.

Mapping of stakeholders and their interactions provides the basis for the analysis of the potential for market development of the different scenarios as thrown up by the pilots. Different pilots have their own dynamics in terms of the following elements:

- Their positioning with respect to the three impact scenarios of user engagement, user interaction and community co-design.

- The set of stakeholders involved in developing the pilot requirements and scenarios

- The role of the project partner responsible for the pilot within that stakeholder community

\section{Social Validation}

The SDI4Apps team combines partners covering the entire chain from data providers, technological developers and geospatial data experts to final end users. The consortium includes partners involved in Living Labs which is part of the overall methodology for the platform integration and social validation. The Living Labs approach, as an essential building block of SDI4Apps, is aimed to structure wide-spread end-user participation in new technologies' integration and adoption, and in research and new innovation activities. (Schade and Granell, 2014).

The SDI4Apps methodology is not using the following standard sequence of actions of pilot projects:

\section{User requirements $\rightarrow$ Design $\rightarrow$ Development $\rightarrow$ Deployment $\rightarrow$ Testing}

Instead SDI4Apps is following a different approach, as:

1. The majority of EU projects are collecting new requirements which in most cases overlap, 
2. There already exists many implementations of state of the art technologies, and user requirements collection is not leading to any progress,

3. Users are interested in getting results as soon as possible, and standard project methodologies do not deliver satisfying results in time.

For these reasons SDI4Apps is using the following very different user-driven approach:

(1) Deployment of SDI4Apps Cloud platform (state of art technologies, Open Tools)

$\rightarrow$ (2) User experimentation and social validation in real-world scenarios

$\rightarrow$ (3) Feedback from the SDI4Aps community

$\rightarrow$ (4) Redesign

$\rightarrow$ (5) Improvement of the SDI4Apps Cloud Framework

$\rightarrow$ (6) User experimentation and social validation in real-world contexts $\rightarrow 2$ ) (Figure 8)

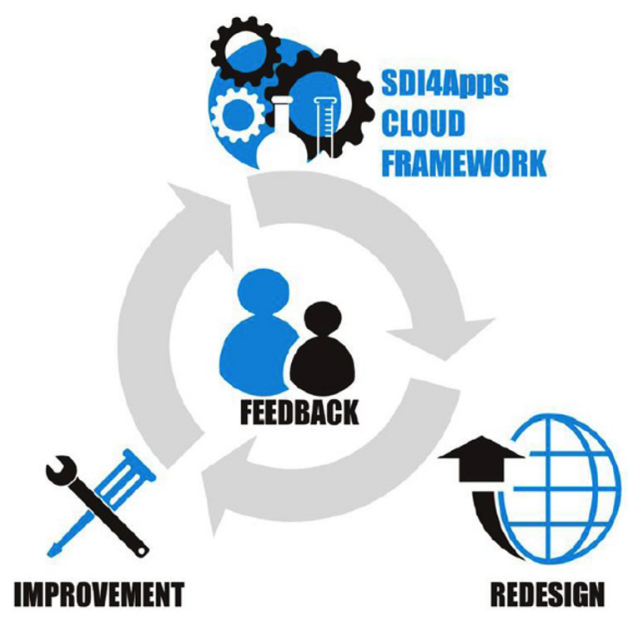

Source: Charvat, Mildorf, Tuchyna, Vohnout and Krivanek, 2014 Figure 8: SDI4Apps Approach to User Validation.

SDi4Apps is bringing together the demanddriven power of the market-oriented solutions and the institutional legitimacy of INSPIRE/ $\mathrm{OD} / \mathrm{LOD}$, which places the public interest before commercial needs. The approach is based on social validation, a process which engages "those who will adopt" within institutionally framed pilot experiments in the 6 diverse pilots. The social validation is being provided by defining Use Cases in the User Scenarios of each pilot, according to a defined methodology and common structured description, based on:

- Community Building and Engagement
- Emerging Business Models

- Added Value of the SDI4Apps platform

- Interoperability with other SDI4Apps Pilots

Thus central to validation of the SDI4Apps pilots are user and community actions that aim to both build individual and collective assets by better understanding and potentially improving the effectiveness and transparency of the interaction amongst different organizational and institutional contexts which govern the use of these assets.

In particular, SDI4Apps is extending to the cloud, an environment with an open API based on Open Source components. This platform, which is an extension of the current INSPIRE architecture, incorporates the basic principles of neogeography (Goodchild, 2009) and Volunteered Geographic Information (VGI) (Spinsanti,and Ostermann, 2013). These community-based techniques are being used as the main building blocks of the SDI4Apps social validation. It is allowing users and data providers to test existing technologies, customise solutions for their purposes and thereby generate further research tasks through user-driven processes.

The methodology and methods for multistakeholder analysis adopted for implementation in the SDI4Apps social validation builds on the tradition of community-based participatory research (Francisco and Butterfoss, 2007), asking a number of evaluative questions to assess how involved end-users and more generally the overall population are affected by a given intervention, project or programme. A key methodological reference point is the Living Labs/SSRI (Social Spaces for Research and Innovation) (SSRI) approach to deal with the social, organisational and institutional dimensions of innovation in parallel with the technical aspects, and to engage in validation activities with all user groups, stakeholders, and content providers in an open and inclusive way, supported by the SDI4Apps platform and tools.

In the early evaluative rounds that being carried out within the SDI4Apps project, social validation is related to the benefits associated with the deeper involvement of actual end-users in data access and service co-creation, according to the Living Labs user-centred open-innovation approach. In a conceptual definition of the social validation "space", the focus of application for behavioural analysis to ensure its credibility (Flanagin and Metzger, 2008) is threefold, namely: 


\section{The social significance of stated goals.}

- Do the specific development objectives correspond to what users really want?

- Are they fulfilling a need that is shared by the prospective end users?

- Does the broader community in which the SDI4Apps infrastructure is located value the new services as important to them?

2. The social appropriateness of followed procedures.

- Do the ends justify the means?

- Do users feel that they have a voice in SDI4Apps infrastructure improvement?

- How do they feel they are included in the development, implementation and assessment process?

- Do users and/or local stakeholders consider the procedures for their involvement acceptable?

- Do they recommend them in other situations?

3. The social importance of obtained effects.

- Are end users satisfied with all of the results, including any unpredicted ones?

- Do domain experts value the effects and believe that they were indeed caused (or facilitated) by services developed using the SDI4Apps platform?

- Does the broader community appreciate the outcomes?

- Does it value them as something that should be extended to other domains?

Basically we look at what happened, and ask "Did it matter ?".

The objective of the SDI4Apps Social Validation methodology was first of all to identify specific criteria and indicators of success according to the different standpoints of the actors represented in each usage scenario, as a framework for evaluating the added value of the services that conform to the standards proposed by SDI4Apps. This activity did not start from scratch, but took into account the taxonomy of social validation approaches elaborated in the HABITATS project (Navarro and Saez, 2013), i.e.

- Validation driven by the prospect of user engagement

In this case end-users are not yet directly involved in social validation, but the prospect of user engagement is already influencing institutional behaviour.

- Validation through direct user interaction with the open data access process

With the direct participation of (expert/ non expert) users in data access.

- Validation driven by the co-design of innovative "demand pull" services.

This is the most user-driven approach, as it actually involves final end-users in the co-design of services that use the SDI4Apps platform.

The indicator sets that have been defined so far are matched with a composite list of evaluative questions used for the pragmatic assessment of impact generated by the Apps and services enabled by the SDI4Apps platform on each of the six pilot scenarios - and more broadly, on the environmental related activities in which users are involved.

Using this method, the following table shows a broad initial estimate of the mapping of the 6 SDI4Apps Pilots from the structured descriptions of the User Scenarios (Table 1).

\begin{tabular}{|l|c|c|c|}
\hline Pilot \& Validation Approaches. & $\begin{array}{c}\text { Validation driven } \\
\text { by the prospect } \\
\text { of user engagement }\end{array}$ & $\begin{array}{c}\text { Validation through } \\
\text { direct user interaction } \\
\text { with the open data } \\
\text { access process }\end{array}$ & $\begin{array}{c}\text { Validation driven } \\
\text { by the co-design } \\
\text { of innovative "demand } \\
\text { pull" services }\end{array}$ \\
\hline P1. Easy Data Access & $\mathrm{X}$ & $\mathrm{X}$ & $\mathrm{X}$ \\
\hline P2. Open Smart Tourist Data & $\mathrm{X}$ & $\mathrm{X}$ & $\mathrm{X}$ \\
\hline P3. Open Sensor Network & & $\mathrm{X}$ & \\
\hline P4. Open Land Use Map through VGI. & $\mathrm{X}$ & & $\mathrm{X}$ \\
\hline P5. Open INSPIRE4Youth/ education & $\mathrm{X}$ & $\mathrm{X}$ & \\
\hline P6. Ecosystem Services Evaluation. & & & \\
\hline
\end{tabular}

Source: SDI4Apps Social Validation Methodology

Table 1: SDI4Apps Pilots \& Validation Approaches. 


\section{Success criteria}

The social validation includes criteria for measuring the SDI4Apps platform's success, methods for multi-stakeholder social participation, analysis for internal and external communities and also a set of indicators, which is measured during the validation process based on structured pilot scenarios.

The methodology involves evolving these structured descriptions as the project and social validation develops with the communities involved. Using these structured descriptions of the 6 pilots (identified as P1 to P6 in Tables 1 and 2), the validation approach and initial mapping of each pilot's metrics and criteria of success have been identified, and the following mapping of each pilot's own success criteria for the communities involved have been identified (Table 2).

These Success Criteria for the SDI4Apps platform in each of the 6 User Scenarios has a number of issues:

1. In some cases it may be difficult to evaluate each scenario. There may be licensing issues of software components specific to certain scenarios.

2. There may be limited access to certain data - either not permitted or restricted - and the source data may need to be modified

3. One option is to use training materials prepared to assess the usability and functionality scenarios.

4. For the initial external evaluation scenarios it is necessary to prepare a set of criteria/ questions that can be targeted at specific problems and scenarios.

5. Are the scenarios understandable for developers?

Following through on the methodology, the initial set of required SDI4Apps platform's Enabler functions that the pilots require have been grouped by its Basic and Extended Functionalities (Table 3).

These user required 9 functionalities and 15 Enablers provide input to and are now being implemented in the SDI4App platform (SDI4Apps Architecture).

\section{Results and discussion}

Implementation of the SDI4Apps Social Validation methodology is both light and effective. It has been developed from the work and experience of other projects such as HABITATS,

\begin{tabular}{|c|c|c|c|c|c|c|c|}
\hline $\begin{array}{l}\text { Pilot \& } \\
\text { Validation } \\
\text { Approaches }\end{array}$ & Each Pilot Community's Criteria of Success & P1 & P2 & P3 & P4 & P5 & P6 \\
\hline \multirow{5}{*}{$\begin{array}{l}\text { Validation } \\
\text { driven } \\
\text { by the } \\
\text { prospect } \\
\text { of user } \\
\text { engagement }\end{array}$} & Usage level \& Social Validation of Services that use SDI4Apps & $\mathrm{X}$ & $\mathrm{X}$ & $\mathrm{X}$ & $\mathrm{X}$ & $\mathrm{X}$ & $\mathrm{X}$ \\
\hline & Easy collection of information using smart phones \& LOD & $\mathrm{X}$ & & & & & \\
\hline & More Young People using GI services & & & & & $\mathrm{X}$ & \\
\hline & Sustainable support of tourism with ESS methodology \& datasets. & & & & & & $\mathrm{X}$ \\
\hline & Local youth educational environmental \& cultural heritage apps. & & & & & $\mathrm{X}$ & \\
\hline \multirow{6}{*}{$\begin{array}{l}\text { Validation } \\
\text { through } \\
\text { direct user } \\
\text { interaction } \\
\text { with open } \\
\text { data access } \\
\text { processes }\end{array}$} & Integration of VGI into existing SDIs \& LOD & $\mathrm{X}$ & & & & & \\
\hline & Integrate VGI with low cost sensors in local web sensor networks & & & $\mathrm{X}$ & & & \\
\hline & Increased access to harmonised \& interoperable GI, L/OD\& VGI data & $\mathrm{X}$ & $\mathrm{X}$ & $\mathrm{X}$ & $\mathrm{X}$ & $\mathrm{X}$ & $\mathrm{X}$ \\
\hline & Integrate data from users', OD, crowd-sourced \& social media. & $\mathrm{X}$ & $\mathrm{X}$ & & & $\mathrm{X}$ & \\
\hline & VGI Open Land Use Mapping & & & & $\mathrm{X}$ & & \\
\hline & Availability of Valuation map of ecosystems with UI \& API & & & & & & $\mathrm{X}$ \\
\hline \multirow{4}{*}{$\begin{array}{l}\text { Validation } \\
\text { driven by } \\
\text { co-design of } \\
\text { innovative } \\
\text { "demand } \\
\text { pull" } \\
\text { services }\end{array}$} & Reuse \& share tourist information resources, channels \& tools & $\bar{X}$ & $\bar{X}$ & & & & \\
\hline & SMEs, Students \& Researchers developing new Apps & $\mathrm{X}$ & $\mathrm{X}$ & $\mathrm{X}$ & $\mathrm{X}$ & $\mathrm{X}$ & \\
\hline & New tourism activities, visitors \& jobs, and SME developed services. & $\mathrm{X}$ & $\mathrm{X}$ & & $\mathrm{X}$ & & \\
\hline & & & & & & & \\
\hline
\end{tabular}

Source: SDI4Apps Social Validation Methodology

Table 2: Validation approach \& Initial mapping of each Pilot's Success Criteria. 


\begin{tabular}{|c|c|c|c|c|c|c|c|}
\hline $\begin{array}{l}\text { SDI4Apps } \\
\text { Functionality }\end{array}$ & SDI4Apps Enablers & 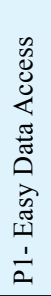 & 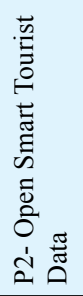 & 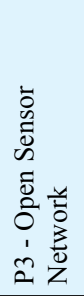 & 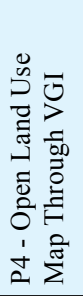 & 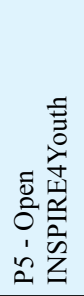 & 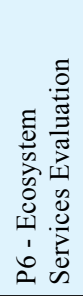 \\
\hline $\begin{array}{l}\text { Advanced } \\
\text { visualisations }\end{array}$ & $\begin{array}{l}\text { 1. Advanced Visualisation framework \& API } \\
\text { (of GI \& non-GI components) }\end{array}$ & $\mathbf{X}$ & $\mathbf{x}$ & $\mathbf{X}$ & $\mathbf{X}$ & $\mathbf{X}$ & $\mathbf{X}$ \\
\hline \multirow{3}{*}{$\begin{array}{l}\text { Data } \\
\text { harmonisation }\end{array}$} & $\begin{array}{l}\text { 2. Scalable GI to LOD transformation and harmonisation } \\
\text { service, from many heterogeneous database sources, } \\
\text { including HALE [HALE] support. }\end{array}$ & $\mathbf{X}$ & $\mathbf{X}$ & $\mathbf{X}$ & & & $\mathbf{X}$ \\
\hline & 3. Validation and integration tools & & & & $\mathbf{X}$ & $\mathbf{X}$ & $\mathbf{X}$ \\
\hline & 4. Scalable publishing of harmonised data sets. & & & & $\mathbf{X}$ & $\mathbf{X}$ & $\mathbf{X}$ \\
\hline $\begin{array}{l}\text { Integration } \\
\text { of mobile apps }\end{array}$ & $\begin{array}{l}\text { 5. Scalable crowdsourced/VGI real-time data collection } \\
\text { with Open API. }\end{array}$ & $\mathbf{X}$ & $\mathbf{X}$ & & $\mathbf{X}$ & $\mathbf{X}$ & \\
\hline \multirow{5}{*}{$\begin{array}{l}\text { Interoperability } \\
\text { between local } \\
\text { and global } \\
\text { geospatial models. }\end{array}$} & $\begin{array}{l}\text { 6. Scalable Geo-focused Crawler for automatic } \\
\text { collection of OGC services endpoints representing } \\
\text { spatial content available via the deep web. }\end{array}$ & $\mathbf{X}$ & & & $\mathbf{X}$ & & $\mathbf{X}$ \\
\hline & $\begin{array}{l}\text { 7. Scalable intelligent deep-Web GI/LD Search } \\
\text { \& discovery with Open API }\end{array}$ & & $\mathbf{X}$ & $\mathbf{X}$ & & $\mathbf{X}$ & \\
\hline & $\begin{array}{l}\text { 8. Scalable Smart Sensor Networks and SensorML } \\
\text { support, to extend the PPP FI ENVIROFY Specific } \\
\text { Enablers [ENVIROFI] }\end{array}$ & & & $\mathbf{X}$ & & & \\
\hline & 9. Interoperable scalable access to sensors & & & $\mathbf{X}$ & & & \\
\hline & 10. Analytical and modelling toolset & & & & & & $\mathbf{X}$ \\
\hline \multirow{3}{*}{ Linked Open Data } & $\begin{array}{l}\text { 11. Scalable INSPIRE GI schema to LOD transformation } \\
\text { and harmonisation service, with persistent URIs. }\end{array}$ & $\mathbf{x}$ & & & $\mathbf{X}$ & & $\mathbf{X}$ \\
\hline & $\begin{array}{l}\text { 12. Scalable RDF Triple Storage service for LD } \\
\text { (such as Virtuoso) }\end{array}$ & $\mathbf{X}$ & $\mathbf{X}$ & $\mathbf{X}$ & $\mathbf{X}$ & $\mathbf{X}$ & $\mathbf{X}$ \\
\hline & $\begin{array}{l}\text { 13. Semantic indexing infrastructure to transform GI } \\
\text { to LOD }\end{array}$ & $\mathbf{X}$ & $\mathbf{X}$ & & $\mathbf{X}$ & $\mathbf{X}$ & \\
\hline \multirow[t]{2}{*}{$\begin{array}{l}\text { Scalable execution } \\
\text { of spatial models }\end{array}$} & $\begin{array}{l}\text { 14. Scalable fast PostGIS and concurrent PostgreSQL } \\
\text { support, providing clustered real-time updates on all } \\
\text { master databases. }\end{array}$ & & $\mathbf{X}$ & & $\mathbf{X}$ & & $\mathbf{X}$ \\
\hline & 15. Scalable GeoServer implementation & & & & $\mathbf{X}$ & & $\mathbf{X}$ \\
\hline
\end{tabular}

Source: SDI4Apps Social Validation Methodology

Table 3: SDI4Apps Functionality Enablers required by the Pilots.

Plan4All, Plan4Bussiness and SmartOpenData. The methodology basically consists of iteratively presenting in a structured way the best practice SDI4Apps platform to the various stakeholder communities and asking them what they want of it and how well it meets their needs, and then improving it. The methodology involves the SDI4Apps partners, users' and developers' communities, meetings, observations, surveys and other evaluation techniques to track progress against agreed indicators, as discussed above. The process and methods consists of:

1. Identifying the stakeholder communities of:

1. Users - represented by the 6 Pilots and operation of their user scenarios

\section{Developers -}

1. represented initially by the consortium's internal partners, and

2. later by the external developer communities that will be addressed through the activities to support External Developers

2. Asking the communities what they want in the context of what the SDI4Apps platform and tools can deliver, by:

1. Providing the SDI4Apps infrastructure based on "best practice" architecture and tools from previous work

2. Developing a coherent Social Validation Methodology, Plan and Indicators (SDI4Apps 
Social Validation Methodology).

3. Checking if the communities are satisfied, by:

1. Internal validation of the pilots and their users.

2. External validation of user and developer communities using the SDI4Apps Platform to enable services beyond the pilots.

The SDI4Apps Social Validation Methodology involves communities of stakeholders that the partners define who and where they are:

1. End Users - particularly in the pilots

2. Developers

1. Internal - to define the SDI4Apps Architecture and basic cloud functionality

2. External - to take-up the open source SDI4Apps APIs and modules for new services.

3. Pilots - leveraging previous and existing work in defining Scenarios in terms of:

1. Use Cases

2. Datasets

3. Applications and Services.

Evaluation of the SDI4Apps tools is based on community co-defined Use Cases in the User Scenarios of each pilot, in a structured format that describes the stories and context behind why a specific user or user group comes to a service or App. They note the goals and questions to be achieved and sometimes define the possibilities of how the user(s) can achieve them on the site. Scenarios are a critical method for both designing an interface and usability testing.

The methodology involves the scenarios being carried out even before they are implemented. This is based on tabulated documentation of advance knowledge of the criteria and target evaluation scenarios, and as understood by developers. This results in better implementation of the SDi4Apps platform's tools.

Good scenarios are concise but answer the following key questions (Scenarios):

- Who is the user? Using the personas that have been developed to reflect the real, major user groups coming to the service.

- Why does the user come to the service? Noting what motivates the user to come to the service and their expectations upon arrival, if any.

- What goals does he/she have? Through task analysis, we can better understand what the user wants of the service and therefore what it must have for them to leave satisfied.

- How can the user achieve their goals using the service? Defining how the user can achieve his/ her goal on the service, identifying the various possibilities and any potential barriers.

Each evaluation criterion is not being evaluated by all evaluators but is being targeted at specific groups of evaluators. The potential user groups that are being addressed include:

- SDI4Apps Integrators: people who have to use heterogeneous GI to meet the requirements of their daily work (e.g. integration of LOD for complex analysis). They need the actual data and access this from different facilities potentially in different formats. They have to combine various data sources and harmonise them to make use of them for their own purposes. This group should understand the SDI4Apps platform as an efficient toolset to support the required data processing. They are mainly service providers.

- SDI4Apps Users: consist of a large group of people who want to solve a problem and decides to use LOD for their applications / purposes - they are not interested in the harmonization of data resources itself but only in its results. Two subgroups are distinguished within this user role:

- SDI4Apps Development of LOD: users who are directly working with or create LOD. They transform heterogeneous GI sources and create either LOD in an already harmonised form, or LOD that doesn't need harmonisation or integration at all. They make further application modules using LOD for end users.

- SDI4Apps End-Users of Applications: people who do not use LOD directly, they only use information arising from it (indirect use of LOD) or directly use applications. Most commonly they are users at a layman level, e.g. people using navigation systems, online routing services, etc.

Implementation of Social Validation in SDI4Apps involves the 3 dimensions of Social, Technical and Validation activities as illustrated in the following table over the 3 yearly periods 
of the project (Table 4).

In year 1 the project has undertaken the following twin track parallel work:

1. Technical: Provide the SDI4Apps Architecture and Basic Functionality

2. Social: Build the Communities for Social Validation

Then in years 2 and 3 the project is focusing on validation in the parallel tracks of:

1. Social: Undertake the Internal Community Validation and Pilots.

2. Social: Build external Communities \& Validation.

3. Technical: Add extended functionality.

These SDI4Apps activities aim to achieve the following major Social Validation Indicators (SVI) of the project (table 5).

To monitor progress of this plan the SVIs indicate how well the SDI4Apps Platform is meeting the needs of its stakeholder communities. The SVIs' focus is very much on WHAT, not HOW the various users' needs are being addressed, particularly in the pilots.

\section{Conclusions}

Any SDI/LOD platform should be seen as an evolving concept that sustains (or mediates) various perspectives or stakeholders' views. Depending on the user's interest and role within the broader community, its design and implementation (as well as the corresponding assessment process) gets reshaped by a continuous negotiation and renegotiation with all involved actors. In addition, 'space' - or the ultimate object of any SDI/LOD Platform - is socially produced as well, which makes the validating role of socio-technical platforms such as that of the SDI4Apps social validation even more important.

It is envisaged that the robust stakeholder involvement central to SDI4Apps will not only generate sustainable economic returns through the interface between the users, SMEs and scientific communities, but guarantees a solid contribution to the knowledge-driven economy and environmental management across Europe.

\begin{tabular}{|l|l|c|c|c|}
\hline SDI4Apps Dimension & Activity & Y1 & Y2 & Y3 \\
\hline Social & Social Validation Methodology & X & & \\
\hline & Community Building \& Support & $\mathbf{X}$ & $\mathbf{X}$ & $\mathbf{X}$ \\
\hline Technical & Basic Cloud Functionality & $\mathbf{X}$ & & \\
\hline & $\begin{array}{l}\text { Extended Functions \& Data } \\
\text { transformation }\end{array}$ & & $\mathbf{X}$ & $\mathbf{X}$ \\
\hline Validation & Internal Validation \& Pilots & & $\mathbf{X}$ & $\mathbf{X}$ \\
\hline & External Validation \& OSS Communities & & & $\mathbf{X}$ \\
\hline
\end{tabular}

Source: SDI4Apps Social Validation Methodology

Table 4: SDI4Apps Social, Technical \& Validation Activities.

\begin{tabular}{|l|l|l|l|}
\hline SDI4Apps Dimension & \multicolumn{1}{|c|}{ Year 1 } & \multicolumn{1}{c|}{ Year 2 } & \multicolumn{1}{c|}{ Year 3 } \\
\hline Technical & $\begin{array}{l}\text { Architecture \& Basic } \\
\text { Functionality }\end{array}$ & Extended Functions. & Wider SDI4Apps Services. \\
\hline Social & Build Communities & $\begin{array}{l}\text { Internal Pilots, } \\
\text { Internal Developers }\end{array}$ & $\begin{array}{l}\text { Wider Communities, } \\
\text { External Developers }\end{array}$ \\
\hline Validation & Define methodologies. & Apps \& APIs & New service possibilities. \\
\hline
\end{tabular}

Source: Charvat, Mildorf, Tuchyna, Vohnout and Krivanek, 2014

Table 4: SDI4Apps Social, Technical \& Validation Activities. 
Corresponding author:

Dr. John O'Flaherty

The National Microelectronics Applications Centre Ltd, National Technology Park, Limerick, Ireland

E-mail: J.oflaherty@mac.ie

\section{References}

[1] Abbas, S., Ojo, A. Towards a linked geospatial data infrastructure, $2^{\text {nd }}$ Joint International Conference on Electronic Government and the Information Systems Perspective, and Electronic Democracy, EGOVIS/EDEM 2013; Prague; Czech Republic; 26 August 2013 through 28 August 2013; Code 100240, Lecture Notes in Computer Science (including subseries Lecture Notes in Artificial Intelligence and Lecture Notes in Bioinformatics), Vol. 8061 LNCS, 2013, p. 196-210. ISSN 03029743, ISBN 978-364240159-6.

[2] Elwood, S., Goodchild, M. F., Sui, D. Z. Researching Volunteered Geographic Information: Spatial Data, Geographic Research, and New Social Practice, Annals of the Association of American Geographers. 2012, Vol. 102, No. 3, p. 571-590. ISSN: 00045608.

[3] ENVIROFI. Specific Enablers for the environmental Usage Area within the Future Internet Public Private Partnership programme (FI-PPP). [Online] Available: http://catalogue.envirofi.eu/ [Accessed: 26 Aug.2014].

[4] Flanagin, A. J., Metzger, M. J. The credibility of volunteered geographic information, GeoJournal, 2008, Vol. 72, No. 3-4, p. 137-148. ISSN 03432521.

[5] Francisco, V. T., Butterfoss, F. D. Social Validation of Goals, Procedures, and Effects in Public Health, Health Promotion Practice. 2007, Vol. 8, No. 2, p. 128-133. [Online] Available: www.ncbi. nlm.nih.gov/pubmed/17384403 [Accessed: 26 Aug.2014].

[6] Goodchild, M. NeoGeography and the nature of geographic expertise, Journal of Location Based Services. June 2009, Vol. 3, No. 2, p. 82-96. ISSN 17489725.

[7] HALE. HUMBOLDT Alignment Editor. [Online] Available: https://joinup.ec.europa.eu/software/ hale/description [Accessed: 26 Aug.2014].

[8] Charvat, K., Mildorf, T., Tuchyna, M., Vohnout, P., Krivanek, Z. SDI4Apps, 2014 IST-Africa Conference and Exhibition Conference Proceedings. ISBN: 978-190582444-1.

[9] ICT-ENSURE. European Union Framework Seven project ICT for Environmental Sustainability Research, Grant Agreement number 224017. [Online] Available: www.ict-ensure.eu [Accessed: 26 Aug. 2014].

[10] Karam, R., Melchiori, M. A crowdsourcing-based framework for improving geo-spatial open data, 2013 IEEE International Conference on Systems, Man, and Cybernetics, SMC 2013; Manchester; United Kingdom; 13 October 2013 through 16 October 2013; Category number E5154; Code 102429. ISBN: 978-076955154-8.

[11] Kritikos, K., Rousakis, Y., Kotzinos, D. Linked open GeoData management in the cloud, $2^{\text {nd }}$ International Workshop on Open Data, WOD 2013; Paris; France; 2 June 2013 through 2 June 2013; Code 102309, ACM International Conference Proceeding Series, 2013. ISBN: 978-145032020-7.

[12] Metzger, M. J., Flanagin, A. J., Medders, R. B. Social and heuristic approaches to credibility evaluation online, Journal of Communication,Sept. 2010, Vol. 60, No. 3, p. 413-439. ISSN 00219916.

[13] Navarro, M., Saez, A. INSPIRE and Social Empowerment for Environmental Sustainability - Results from the HABITATS project. [Online] Available: www.inspiredhabitats.eu/index. php?option $=$ com_content\&view $=$ article\&id=86\&Itemid=119 [Accessed: 26 Aug. 2014)]. ISBN-13; 978-84-616-3646-4.

[14] Norton, B., Krummenacher, R. Geospatial linked open services, Workshop Towards Digital Earth: Search, Discover and Share Geospatial Data 2010, DE 2010 - Future Internet Symposium; Berlin, Germany; 20 Sept. 2010 through 20 Sept. 2010; Code 101301, CEUR Workshop Proceedings, 2010, Vol. 640, p. 4. ISSN: 16130073. 
[15] Scenarios. [Online] Available: www.usability.gov/how-to-and-tools/methods/scenarios.html, [Accessed: 26 Aug.2014].

[16] SDI4Apps Architecture. SDI4Apps Architecture Concept, SDI4Apps deliverable D3.1, July 2014.

[17] SDI4Apps Social Validation Methodology. Social Validation Methodology, SDi4Apps deliverable D2.2, September 2014.

[18] Schade, S., Granell, C. Shaping digital earth applications through open innovation - setting the scene for a digital earth living lab, International Journal of Digital Earth, Aug. 2014, Vol. 7, No. 7, p. 594-612. ISSN 17538947.

[19] Spinsanti, L., Ostermann, F. Automated geographic context analysis for volunteered information, Applied Geography. 2013, Vol. 43, p. 36-44. ISSN 0143-6228.

[20] SSRI. Social Spaces for Research \& Innovation. [Online] Available: www.c-rural.eu/index. php?option=com_content\&task=view\&id=74\&Itemid=2 [Accessed: 26 Aug.2014].

[21] Vilches-Blázquez, L. M., Saquicela, V., Corcho, O. Interlinking geospatial information in the web of data, $15^{\text {th }}$ International Conference on Association of Geographic Information Laboratories for Europe, AGILE 2012; Avignon; France; 24 April 2012 through 27 April 2012; Code 100775, Lecture Notes in Geoinformation and Cartography. 2012, p. 119-139. ISSN 18632351, ISBN 978-364229062-6.

[22] Vohnout, P., Cerba, O., Kafka, S., Fryml, J., Krivanek, Z., Holy, S. SmartTouristData approach for connecting local and global tourist information systems, 2014 IST-Africa Conference and Exhibition, 6 May 2014 through 9 May 2014. ISBN: 978-190582444-1. 